\title{
Local vs. global pragmatics
}

Article

Accepted Version

Borg, E. (2017) Local vs. global pragmatics. Inquiry, 60 (5). pp. 509-516. ISSN 1502-3923 doi:

https://doi.org/10.1080/0020174X.2016.1246862 Available at https://centaur.reading.ac.uk/57622/

It is advisable to refer to the publisher's version if you intend to cite from the work. See Guidance on citing.

To link to this article DOI: http://dx.doi.org/10.1080/0020174X.2016.1246862

Publisher: Taylor \& Francis

All outputs in CentAUR are protected by Intellectual Property Rights law, including copyright law. Copyright and IPR is retained by the creators or other copyright holders. Terms and conditions for use of this material are defined in the End User Agreement.

\section{www.reading.ac.uk/centaur}

\section{CentAUR}

Central Archive at the University of Reading

Reading's research outputs online 


\section{Local vs. Global Pragmatics: a reply to Simons}

\section{Emma Borg}

The problem Mandy Simons addresses in her new paper is a classic objection levelled at anyone of a broadly Gricean persuasion: surely one thing we all know about Grice is that he suggested subjects first derive something like literal sentence meaning (based on word meaning and structure) and then they look to pragmatics to derive speaker meaning (on the basis of that literal meaning). Yet this Gricean ordering, where pragmatics comes second, seems simply wrong. There are clear instances where pragmatics seems required to contribute to literal, sentence-level content. That is to say, sometimes pragmatic effects are embedded or local, as in the truthconditional difference between (1) and (2):

1) If Jill drank 5 beers and drove home then she can be charged with drink driving.

2) If Jill drove home and drank 5 beers then she can be charged with drink driving. It is hugely to Simons' credit that her resolution of the above puzzle - the method by which she makes it seem plausible that the Gricean model can allow for local pragmatic effects - makes one wonder what all the fuss has been about all this time. After reading the paper I couldn't think why we Griceans hadn't just said what Simons says all along, and that is surely the mark of an excellent paper - that it not only offers a solution to a long-standing problem but a solution that serves to dissolve the force of the original objection. Perhaps not everyone will agree, but I was convinced. In this response, then, rather than raising any fundamental objection to the proposal, I want instead to discuss one issue of detail and (following on from this) one possible repercussion of the paper.

The issue of detail concerns Simons' characterisation of the project she aims to defend. At the start she states that: "I take it that to give a Gricean account of some pragmatic phenomenon, we must provide an explicit rational reconstruction of the reasoning that an interpreter might engage in to calculate the speaker's meaning on the basis of the compositionally derived content of the speaker's utterance" (3), and she holds that "[T]here are two central pillars to the Gricean construct. The first [of which] is that what interpreters are trying to do when they interpret is to identify the speaker's communicative intention" (4). ${ }^{1}$ However Simons is also clear that exegetical issues are not her primary concern: she wants to defend a particular model of meaning and communication, one which can be identified as broadly Gricean even if it doesn't match in detail everything that Grice himself believed. In this spirit, however, I'd be inclined to query these two constraints - that what we are doing in a

\footnotetext{
${ }^{1}$ See also n.12 for an expression of ambivalence about the cognitive reality of the Gricean method.
} 
Gricean framework is giving a rational reconstruction and that what we are rationally reconstructing is how subjects recover the communicative intention of the speaker. First, as is well-known, many neo-Gricean models have opted for a much greater degree of cognitive reality than the claim of mere rational reconstruction requires and we might think that, all things considered, an account which seeks to model how interlocutors actually do recover linguistic meaning is, if possible, preferable to one which merely makes a modal claim about how understanding might come about. Second, while it is no doubt right that within the reductive model Grice himself promoted, the aim of reasoning was to recover the unique intention in the speaker's mind which provides the content for the communicative act they have undertaken, we might wonder whether this need be an integral part of a Gricean model broadly conceived. Reflection on our own communicative practices might, I think, cast doubt on this idea of a unique communicative intention and on a model of conversation that accords communicative success just to those cases where hearers successfully recover the very communicative intention entertained by the speaker. I suspect we are more likely to find that speakers often have vague or indeterminate intentions about what they want to communicate to a hearer and communicative success may be a matter of degree depending on the number and identity of the propositions which a hearer takes away from the communicative exchange. So when I say "I like that team" I may not have formed a clear intention in advance to communicate either I like that football team, or I like that woman's football team, or That is the UK football team I like the most, but (in the right context) I might nevertheless be happy with any of these as reasonable or successful interpretations of my utterance. If that's right, we might begin to think that communication (at least on the non-literal, pragmatic side of the divide) may be a much looser, much more stratified matter than the strict Gricean view of recovery of a speaker's communicative intention might have led us to believe. Of course, neither of these points challenge the main thesis of the paper, but if, with Simons, exegetical matters are not our primary concern then I think we should be open to the idea that what counts as a Gricean model, broadly conceived, is more liberal than Simons' perhaps allows here. ${ }^{2}$ Furthermore, this point may matter because the degree of liberality about what counts as a Gricean view may perhaps have implications for more central aspects of the paper.

So, let's turn now to the main contentions of the paper. Take an example Simons discusses at length (renumbered here):

3) A: What will you do for your mother's birthday?

\footnotetext{
2 Though I should note in this regard that other definitions Simons offers of the Gricean model are indeed more liberal than the ones quoted above, for instance: "any account of pragmatic inference which posits that an interpreter reasons about what the speaker meant and that this reasoning is guided by presumptions of rationality of the speaker is a Gricean account" (4).
} 
4) B: Either I'll buy flowers or cook a nice dinner.

As Simons notes, B's utterance as it stands does not provide an answer to A's question, thus there is a failure of relevance. This means a hearer is licensed in interpreting $\mathrm{B}$ as intending to convey something other than the literal meaning of the sentence (in order to preserve the hearer's view of B as a cooperative conversational partner). The interpreter can thus reason: B said $\mathrm{p}$ or $\mathrm{q}$, but $\mathrm{p}$ is not an answer to the question, so cannot be the intended content of the first disjunct. What could the content of this disjunct be then? Well, perhaps B will buy flowers to give to their mother. Gricean reasoning is thus used to enrich the first disjunct and the result is an embedded pragmatic effect. As Simons stresses, local pragmatic effects can be the result of global pragmatic thinking. However, as Simons goes on to discuss there are then two distinct ways in which we could flesh out this recognition: the local versus the global approach. On the local view, we have genuine pragmatic intrusion on what is said: the literal content of what B says is held to include B will buy flowers for B's mother's birtbday. Pragmatic effects (beyond mere reference assignment and disambiguation) are then (contra the original Gricean model) fully embedded in what the speaker directly asserts, they are not merely relevant to ascertaining what the speaker indirectly implicates. The local view, then, is a variety of Contextualist, or Pragmaticist, approach and I take it that those who defend this kind of view (such as Recanati, Sperber and Wilson, Carston and many others) would be happy to embrace the position given here. Indeed they might, I think, hold that the approach to hand is something of a notational variant of their own approach: Sperber and Wilson, for instance, were always keen to stress the Gricean nature of their approach and while they and other Contextualists (see especially Carston, 2002. Thoughts and Utterances. Oxford: Blackwell.) stressed pairs like (1) and (2) as a problem for the traditional Gricean approach, a Gricean model which, with Simons, holds that "there is more to Gricean pragmatics than implicature" (3) would seem to sit very comfortably indeed within the Contextualist canon.

On the other hand, however, Simons also notes that there is an alternative to the local view: according to the global version of the account, we treat the enriched contents as implicatures: "On this view, we say that B says that she will either buy flowers (simpliciter) or cook a nice dinner (simpliciter); and implicates that she will either buy flowers and give them to her mother or cook a nice dinner for her mother" (16). Here we use broadly Gricean mechanisms to arrive at the right (intuitively meant) content but the content thus arrived at is not taken to yield the literal content of B's utterance: these are cases of someone saying one thing but meaning another. "[S]taunch globalists, if they are of a generally Gricean persuasion, should be happy with the analyses I have presented, as they demonstrate that Gricean rational 
reconstructions that derive the appropriate results are available" (18). This global view is bound to appeal to anyone who might have sympathies with a so-called minimalist approach to linguistic meaning (as do I). The minimalist wants to resist the idea of rich, embedded pragmatic effects. Instead she seeks to preserve a strict divide between propositional sentence meaning (which is pragmatics-free, bar disambiguation and reference assignment to genuine indexicals and demonstratives) on the one hand and speaker meaning (where pragmatic influence is endemic) on the other. Thus, for her, the difference between (1) and (2) can only come at the level of pragmatic speaker meaning not literal, semantic sentence meaning. ${ }^{3}$

However it seems to me that while the minimal/global view wants to hang on to this distinction, it might do so whilst nevertheless embracing the idea accorded to the local view that there is more to pragmatics than just unasserted, indirect Gricean implicatures. That is to say, a globalist might reject the existence of any semantically embedded pragmatic effects while allowing (with the localist) that there is more to Gricean pragmatics than just implicature. On this view, when composing word meanings and structure to deliver propositional semantic content there is no role for pragmatics bar the roles Grice himself allowed within his notion of 'what is said by a sentence' (i.e. disambiguation and reference assignment). However, minimalists have always stressed that this compositional semantic content should not be viewed as 'what is said' and that what a speaker communicates by producing a sentence with a given literal meaning may encompass a range of propositions, which vary considerably in the degree of pragmatic influence they display. This kind of globalist, then, would not hold that "B says that she will...buy flowers (simpliciter)" (16), while what B says/asserts is that B will buy flowers for B's mother. What the minimalist wants is a strict divide between sentence meaning and speaker meaning, and the global strategy outlined by Simons could help her to preserve this distinction (by showing how general Gricean mechanisms deliver local pragmatic effects) without necessarily endorsing the view that the results of all instances of such Gricean reasoning are classic Gricean implicatures.

Similarly, just as the globalist view I prefer would allow that there is more to Gricean pragmatics than just implicature, so it might also allow that there is more to pragmatics in general than just Gricean pragmatics. If we allow that speaker meaning is rarely constituted by a single,

\footnotetext{
${ }^{3}$ Note that some Contextualists or Pragmaticists (e.g. Carston) might agree with this way of phrasing things. For them, too, the difference between (1) and (2) can only come at the level of pragmatic speaker meaning not literal, semantic sentence meaning. The key differences between Contextualists of this stripe and Minimalists, then, would be first that the Minimalist (but not the Contextualist) holds that literal sentence meaning is propositional content that words and structure combine in well-formed sentences to guarantee truth-evaluable content. Second, the two approaches deliver different answers to the question of whether there is a level of content (what Sperber and Wilson term the 'explicature'), which is distinct from implicature content and which can be identified in some kind of conversation-independent way, e.g. by using notions like ‘a development of logical form' or 'the proposition which results from filling in the gaps left by mere composition of word meanings'. Minimalism (at least as I construe it) rejects this idea of a special category of somewhat pragmatically enhanced content. Finally, differences on these points are also likely to impact on the view each account proposes for word meanings themselves.
} 
definitive propositional content, rather it embraces an often vague and indeterminate set of (mostly) pragmatically delivered propositions (cf. Cappelen and Lepore's discussions of 'speech act pluralism', in their Insensitive Semantics: a defense of semantic minimalism and speech act pluralism. 2005. Oxford: Blackwell), then this set of pragmatically moderated propositions might be delivered by a wide range of distinct kinds of pragmatic influence. For instance, alongside standard Gricean reasoning processes (using the conversational maxims), we might also allow that pragmatic influences can come from the existence of 'conversational scripts' and stereotypical exchanges, as where an utterance of 'Just these' is heard as expressing that these are the only items I wish to purchase now when uttered at a cash register in a shop, or an utterance of 'Where do you want to go?' expresses the question where do you want to go in this taxi? when asked by a cab driver of a new passenger. There are lots of ways in which context of utterance might contribute to an understanding of what a speaker says and only some of these ways will fit the traditional Gricean model of implicature recovery.

Yet we might well begin to worry now that this is all really just a matter of terminology: both local and global accounts (of the minimal variety sketched above) want to have pragmatically enhanced asserted content, but one insists that this is in addition to propositional sentence-level content and one denies this. The worry that we are dancing on pin heads looms large, and it is a concern Simons gives voice to:

The question remains as to whether there is any evidence which can decide between a localist and a globalist approach...My impression is that there is not...[T] hese choices are driven by theory rather than by empirical observation, and I don't see that the choice makes much difference to the project of modelling how interpreters arrive at particular interpretations of utterances. (18)

If Simons is right that there is no evidence which can decide between the two approaches, the charge of superficiality certainly seems vindicated. However, although I would certainly agree that things are slippery in this area, I've tried to suggest elsewhere (e.g. Borg 2012, Pursuing Meaning, Oxford: Oxford University Press, Chapter 1) that charges that the dispute is mainly terminological are overstated and part of my reason for this concerns the point raised earlier about the sort of broadly Gricean approach one has in mind. ${ }^{4}$ For instance, if one were to think that what one was modelling in constructing a theory here really was the psychological process involved in language understanding then it does seem that the two approaches - the local and the global - would pay off in some genuine and detectable differences. For on a cognitively real version of either approach, the question concerns the psychological mechanisms underpinning linguistic understanding. In exchanges like (1) or (2) and (3)-(4), is there a discrete, propositional,

\footnotetext{
${ }^{4}$ Other reasons for thinking the dispute may be more than merely terminological are more theoretical, for instance: concerns about the account of word meaning Contextualists can provide, issues of learnability and normativity for a language, and concerns about validity.
} 
minimal content being generated within the language faculty (just via word meaning and structure, and 'tame' pragmatics, see Borg 2012), which yields the literal content of the sentence as uttered, or is the only propositional content in the picture the pragmatically enriched proposition(s)? Is linguistic understanding saturated throughout by rich, abductive reasoning processes (the kind of 'all things considered reasoning' that is the hallmark of so much human thought) or does recovery of literal meaning involve only more limited, deductive reasoning? And can grasp of truth-evaluable literal meaning dissociate from pragmatic competence in impairment cases or do the two travel together, preserved or lost as a pair? It is in addressing these sorts of questions, stemming from the empirical study of the minds of language users, that I think we might perhaps hope to find evidence to answer the question of whether the local or the global approach is right. Perhaps this is to go further from the Gricean ancestry than Simons wants to allow, but if we agree with her that what is interesting about the debate is not a slavish desire to vindicate every aspect of the Gricean model but rather a conviction that a certain kind of approach to meaning and communication (as a rational and cooperative process) is right, then it seems to me we should also be willing to consider a more cognitively robust form of Gricean pragmatics than perhaps Grice himself envisaged. ${ }^{5}$

5 Though I would also note that there are exegetical questions as to whether the rational reconstruction view assigned to Grice by Bach (and Saul) is required by the texts themselves. 